\title{
O isolamento é possível? O caso de um povo de recente contato do Vale do Javari
}

\author{
JULIANA OLIVEIRA SILVA \\ Universidade Federal do Rio de Janeiro, Rio de Janeiro, Rio de Janeiro, Brasil \\ anailujoliveiras@gmail.com
}

DOI 10.11606/issn.2316-9133.v29isuplp244-254

\begin{abstract}
resumo No contexto da pandemia da COVID-19, medidas preventivas de "distanciamento social" ou "isolamento" têm sido aclamadas como a principal forma de prevenção e contingenciamento do novo coronavírus. Este artigo, ancorado em trabalho de campo realizado na Terra Indígena Vale do Javari, dedica-se à reflexão das possibilidades de isolamento entre os Korubo, considerados pela Fundação Nacional do Índio como um povo indígena de recente contato. $\mathrm{O}$ esforço de reflexão perpassa $\mathrm{o}$ conceito de isolamento comunitário, enquanto estratégia de contingenciamento da COVID-19, e os deslocamentos envolvidos no atendimento à saúde dos Korubo pela Secretaria Especial de Saúde Indígena.
\end{abstract}

palavras-chave Korubo. Terra Indígena Vale do Javari. Recente contato. COVID-19. Isolamento comunitário.

Is social distance possible? The case of a people of recent contact from Vale do Javari Indigenous Territory

abstract In the context of the COVID-19 pandemic, infection prevention and control measures such as "social distancing" and "isolation" have been hailed as the main strategies to stop transmission of the new coronavirus. Based on the fieldwork research carried out at the Javari Valley Indigenous Territory, the article reflects on the possibilities of such measures among the Korubo people, considered by FUNAI (Brazil's Indigenous agency) a recently contacted Indigenous group. The article addresses the concept of isolation as a contingency strategy for the COVID-19, and the displacements involved in health care for those recently contacted by the Special Secretariat for Indigenous Health.

keywords Korubo. Javari Valley Indigenous Territory. Recent contact. COVID19. Community isolation. 


\section{¿Es posible el aislamiento social? El caso de un pueblo de recién contacto en el territorio indígena Vale do Javari}

resumen En el contexto de la pandemia del COVID-19, las medidas preventivas de "distanciamiento social" o "aislamiento" han sido aclamadas como la principal forma de prevención y contingencia del nuevo coronavirus. Este artículo está basado en la labor de campo realizada en el Territorio Indígena del Vale do Javari, y reflexiona sobre las posibilidades de aislamiento entre los Korubo, considerados por la Fundación Nacional del Indio como un pueblo indígena de contacto reciente. El esfuerzo de reflexión impregna el concepto de aislamiento comunitario, como estrategia de contingencia de COVID-19, y los desplazamientos que implica la atención sanitaria de los Korubo por parte de la Secretaría Especial de Salud Indígena Brasileña.

\section{Introdução ${ }^{1}$}

O histórico de vulnerabilidade dos povos indígenas diante de doenças respiratórias, uma das maiores causas de mortalidade infantil, tem sido destacado por diversos pesquisadores e profissionais ao preverem os impactos da COVID-19 sobre essas populações, como no "Plano de Contingência Nacional para Infecção Humana pelo novo Coronavírus (COVID-19) em Povos Indígenas", elaborado pela Secretaria Especial de Saúde Indígena (SESAI) no Brasil.

Neste artigo, abordarei a situação de um povo indígena considerado pela Fundação Nacional do Índio (FUNAI) como "recente contato": os Korubo. Essa narrativa baseia-se em pesquisa de campo para fins de doutoramento, realizada entre janeiro/2019 e fevereiro/2020 na Terra Indígena (TI) Vale do Javari, interrompida pela chegada do novo coronavírus ao Brasil e a consequente Portaria n419/2020/FUNAI que, dentre outros aspectos, restringiu o acesso de civis às terras indígenas para conter a expansão da pandemia.

Os Korubo pertencem ao ramo setentrional da família linguística pano (ERIKSON, 1996; FLECK, 2013; OLIVEIRA, 2013) e habitam um território ancestral na sub-bacia hidrográfica do rio Itaquaí, um afluente do baixo rio Javari, fronteira natural entre Brasil e Peru, atualmente dentro dos limites da TI Vale do Javari. Com extensão de 8,5 milhões de hectares, localizada no sudoeste do estado do Amazonas, a TI Vale do Javari é um território compartilhado por sete povos, homologado e registrado em 02 de maio de 2001, atualmente com 6.317 pessoas (SESAI, 2020), e abriga também uma das maiores

\footnotetext{
${ }^{1}$ Este artigo foi utilizado como uma das fontes documentais para a composição do Relatório Técnico $n^{\circ}$ 112/2020-PGR/SPPEA/ANPA, do Ministério Público Federal, solicitado pela 6a Câmara de Coordenação e Revisão, destinada a acompanhar o cumprimento da política indigenista na proteção da saúde dos povos indígenas isolados e de recente contato diante da pandemia da COVID-19, intitulado "O contágio da covid-19 no Vale do Javari: uma situação de emergência em saúde indígena” (COUTINHO JUNIOR, 2020, p. 51-53).
} 
concentrações de povos indígenas em isolamento (cf. RICARDO; GONGORA, 2019, p. $24-5)^{2}$

De acordo com pesquisas como a realizada pelo Instituto Socioambiental em parceria com o Centro de Sensoriamento Remoto da Universidade Federal de Minas Gerais, no Brasil, o Vale do Javari é uma das regiões mais vulneráveis à pandemia em consequência da distância em relação às unidades hospitalares de média-alta complexidade, do elevado contingente de povos indígenas isolados e do reduzido contingente de pessoas com mais de sessenta anos, $5 \%$ do total - cujos eventuais óbitos representariam perdas irreparáveis $^{3}$. Soma-se a isso a presença de invasores: narcotraficantes, missionários, caçadores, pescadores e garimpeiros ilegais. ${ }^{4}$ A esses fatores somam-se os antecedentes epidemiológicos da região. ${ }^{5}$

Desde os anos 1960 já havia registro de casos de tuberculose no Vale do Javari. Entre os anos 1970-80, epidemias de gripe atingiram um povo naquela época recentemente contatado pela FUNAI: os Matis. Nos anos 1980 registraram-se casos de pneumonia, sarampo, tuberculose e doenças sexualmente transmissíveis. Em 1990, a epidemia de cólera chegava à região pela fronteira com o Peru e municípios do entorno (SELAU, 1991; NASCIMENTO; ERIKSON, 2006). Ao longo dos anos 1990 interpuseram-se epidemias de cólera, malária, coqueluche e hepatites virais que, a partir dos anos 2000, se tornaram o principal problema sanitário no Vale do Javari, junto a doenças emergentes, como mansonelose e meningite (SAMPAIO et al, 1996; MSF, 1999; NASCIMENTO; PAREDES, 2006). O inquérito sorológico realizado entre 2006-2007 pela então Fundação Nacional de Saúde mostrou que quase $50 \%$ da população da TI já tivera contato com o vírus da hepatite B, inclusive os Korubo recém contatados (COUTINHO JUNIOR., 2008, p.139).

\section{Isolamento comunitário e dependência institucional}

Considerando que o novo coronavírus é inédito para a população mundial, alguns debates mencionam a ideia de estarmos em situação de "fragilidade compartilhada". Em que medida os recém-contatados realmente compartilham uma fragilidade? E com quem? Os não-indígenas, por um lado, apesar de não conhecerem o novo coronavírus, possuem experiências de contato com doenças diversas; os povos indígenas isolados, por outro lado,

\footnotetext{
2 Atualmente, a FUNAI atua na TI com quatro Bases de Proteção Etnoambiental (BAPE) nos rios Curuçá, Jandiatuba, Quixito e na confluência dos rios Ituí-Itaquaí; e a SESAI assiste dezessete "micro-áreas" com oito "pólos-base". Neste artigo, a sigla "BAPE” fará referência àquela localizada na confluência dos rios Ituí-Itaquaí. ${ }^{3}$ Fonte: https://isa.to/2RNMEJ5. Acesso: 10/05/20.

${ }^{4}$ A União dos Povos Indígenas do Vale do Javari denunciou o retorno de garimpeiros à porção leste da TI em plena pandemia, local onde há presença de isolados korubo. Fonte: https://univaja.com/garimpeiros-voltama-invadir-a-terra-indigena-vale-do-javari-durante-pandemia-da-covid-19/. Acesso 08/05/20.

${ }^{5}$ Sobre saúde no Vale do Javari, conferir Selau (1991), Sampaio et al (1996), Médico sem fronteiras (1999), CTI (2004; 2010), CTI; ISA (2011); Nascimento; Erikson (2006), Nascimento; Paredes (2006), Matos; Marubo (2006), Cesarino; Welper (2006) e Coutinho Junior. (2008).
} 
detêm algum controle estratégico na relação com os não-indígenas (AMORIM, 2018, p. 150), afastando-se relativamente do possível contágio.

Os Korubo de recente contato estão na fronteira entre possuir similar fragilidade imunológica aos isolados ${ }^{6}$ e, simultaneamente, manter contatos esporádicos com invasores e com povos vizinhos na TI Vale do Javari, e contato permanente com agentes institucionais que, caso não nutram uma observância rigorosa dos protocolos de quarentena, se tornarão vetores de transmissão do vírus, conforme ocorreu no mês de junho, quando quatro profissionais de saúde testaram positivo para COVID-19 na aldeia São Luiz do povo Kanamari, no médio rio Javari. ${ }^{7}$

$\mathrm{O}$ isolamento social, enquanto a principal medida de prevenção e contingenciamento da COVID-19, no contexto indígena é avaliado de diferentes formas. Por um lado, representa uma estratégia de vida já adotada por povos isolados e que, atualmente, passou à adesão dos não-indígenas (SHEPARD JUNIOR, 2020). Por outro lado, em contextos díspares, essa medida preventiva diferencia-se em "distanciamento social" e "isolamento comunitário", conforme discutira o antropólogo Luis Felipe Torres acerca do caso Madre de Dios, Amazônia peruana: o primeiro, inviável aos contextos indígenas; e o segundo ideal, porém, um desafio permanente (TORRES, 2020).

Nesse quesito, o caso korubo reflete o contexto indígena mais amplo acerca da não aplicabilidade do conceito de distanciamento social. Além das concepções de pessoa e a centralidade corporal no modo de vida, os hábitos e a infraestrutura das aldeias dificultam: eles vivem em malocas, e usam banheiros e pratos coletivos, para mencionar apenas alguns dos aspectos desafiadores.

Há alguns anos, os Korubo começaram a acessar itens industrializados, mas diferente de algumas realidades indígenas, eles alimentam-se majoritariamente de suas roças, da caça e coleta e, mais recentemente, passaram à apropriação dos materiais nãoindígenas de pescaria. Portanto, conseguem relativamente manter alguma segurança alimentar durante a pandemia, sem precisar sair frequentemente à cidade.

No entanto, no lugar da dependência alimentar, no caso korubo ganha espaço uma dependência institucional em relação à FUNAI e a SESAI, especificamente aos itens que são acessados através dessas instituições, como medicamentos, combustível, sabão, instrumentos de metal, entre outros. Em março/2020, após o informe sobre a chegada do novo coronavírus nas redondezas, duas das quatro aldeias korubo entraram floresta adentro para protegerem-se do vírus - prática adotada por outros povos da TI -, mas não tardou para que retornassem às aldeias em busca de tratamento da SESAI às doenças nãoindígenas. Então, no caso dos Korubo de recente contato, em que medida é possível manter algum isolamento comunitário durante a pandemia?

\footnotetext{
6 Fonte: https://povosisolados.com/2020/05/14/informe-opi-n-2-a-ameaca-do-covid-19-e-o-risco-degenocidio-dos-piirc/. Acesso: 14/05/20.

7 Fonte: https://www.salsa-tipiti.org/covid-19/carta-do-akavaja-associacao-dos-kanamari-vale-do-javari-65-20/. Acesso: 05/06/20.
} 
Quando escrevi a primeira versão deste artigo, a TI Vale do Javari estava no chamado "nível de resposta alerta". ${ }^{8}$ Felizmente, ainda não constam registros de contaminação nas aldeias korubo. Todavia, na TI Vale do Javari já foram confirmados 458 casos e dois óbitos por covid-19. ${ }^{9}$ Diante disso, neste relato ofereço uma pequena lupa para olharmos no cotidiano korubo uma das possíveis brechas de entrada para a COVID-19: os deslocamentos entre as aldeias e a BAPE. Essas saídas das aldeias korubo para a BAPE devem ser pensadas aqui em dois níveis de capacidades: a manutenção do isolamento comunitário e de uma rotina de prevenção - ambas necessárias para o êxito dos planos de contingência, como a primeira versão elaborada pelo Distrito Sanitário Especial Indígena (DSEI) Vale do Javari. ${ }^{10}$

\section{Os deslocamentos no atendimento à saúde dos Korubo}

Os Korubo de recente contato constituem uma população de 127 pessoas, localizada nos rios Ituí e Coari, e uma menina que reside na Casa de Saúde do Índio em Manaus, Amazonas, para tratamento de saúde. ${ }^{11}$ Essa população foi contatada pela FUNAI em 1996, 2014, 2015 e 2019, e está distribuída entre o rio Coari e em quatro aldeias no baixo curso do rio Ituí, próximas à BAPE. ${ }^{12}$ Das 93 pessoas no rio Ituí, cerca de $85 \%$ tem faixa-etária entre 0-34 anos - com maior concentração entre 5-9 anos, 20\% da população total -, e somente quatro pessoas com idade estimada acima dos 50 anos.

Essa população é atendida por uma equipe da SESAI (três a seis profissionais) instalada na BAPE, pois não há polo-base da SESAI nas quatro aldeias korubo do rio Ituí. $\mathrm{Na}$ BAPE, a SESAI construiu uma Unidade Básica de Saúde Indígena (UBSI) para

\footnotetext{
${ }^{8}$ De acordo com o plano de contingência do DSEI Vale do Javari: "O Nível de resposta de Alerta corresponde a uma situação em que o risco de introdução do SARS-COV-2 no território indígena Vale do Javari seja elevado e não apresente casos suspeitos." (2020, p. 06).

9 Fonte: https://saudeindigena1.websiteseguro.com/coronavirus/mapaEp.php\#abrirModal_id12. Acesso: $27 / 08 / 20$.

${ }^{10}$ Quando escrevi a primeira versão deste texto, havia apenas o primeiro plano de contingência do DSEI Vale do Javari. A partir do final do mês de maio/2020, outras iniciativas surgiram, como: um plano de ação e um plano emergencial, ambos da União dos Povos Indígenas do Vale do Javari; e, posteriormente, um segundo plano de contingência do DSEI Vale do Javari. Conferir relatório de Silva e Marques (2020) sobre os dois povos de recente contato da TI Vale do Javari, divulgado pelo Observatório dos Direitos Humanos dos Povos Indígenas Isolados e de Recente Contato. Fonte: https://povosisolados.com/2020/06/21/emergenciasanitaria-no-vale-do-javari-e-a-situacao-dos-povos-de-recente-contato-diante-da-covid-19/. Acesso: $21 / 06 / 20$.

${ }^{11}$ No dia 27 de maio de 2020, essa criança korubo foi diagnosticada com COVID-19 na CASAI Manaus, fora dos limites da TI. Esse é o saldo atual de contaminação por COVID-19 entre os Korubo de recente contato da TI Vale do Javari.

${ }^{12}$ Os Korubo no rio Coari foram contatados pela FUNAI em 2019 e, atualmente, são considerados pelo órgão indigenista oficial como de recente contato. Há ainda uma parcela de Korubo em isolamento na TI Vale do Javari. Referências diretas ou indiretas aos Korubo constam nos arquivos do Centro Ecumênico de Documentação e Informação, na Biblioteca Virtual do Museu do Índio/FUNAI, e em trabalhos acadêmicos, como Erikson (1996), Arisi (2007), Oliveira (2009) e Vargas da Silva (2017).
} 
instalação da equipe de saúde que, além de atender aos Korubo do rio Ituí, realiza eventuais trocas de equipes e/ou transporte de imunobiológicos à outra equipe de saúde que atende os 34 Korubo no rio Coari.

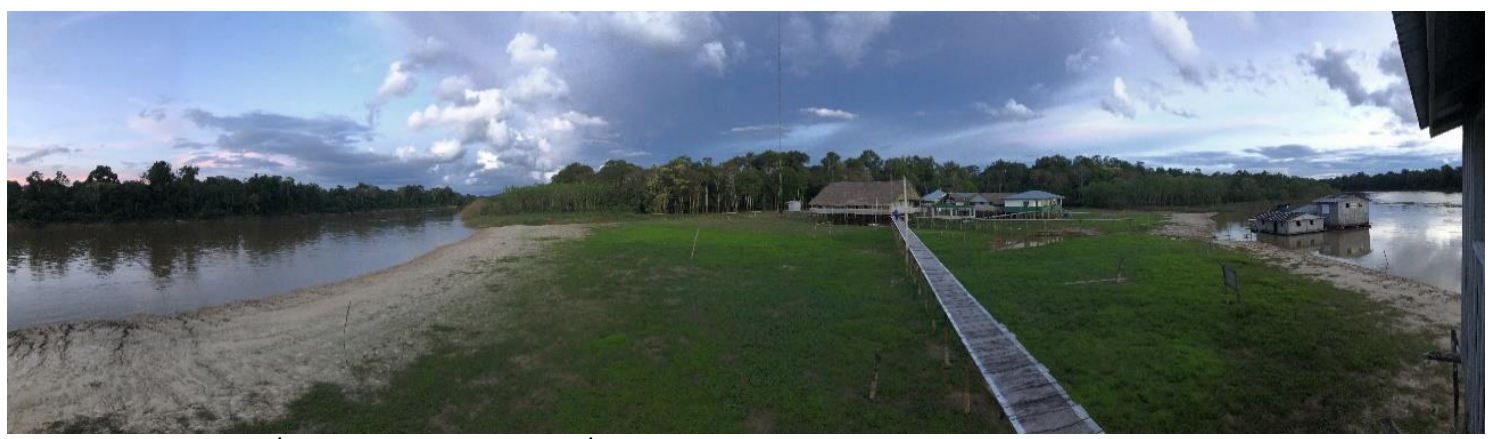

Figura 1. BAPE/FUNAI com UBSI/SESAI (em verde e branco), na confluência dos rios Itaquaí (à esq.) e Ituí (à dir.). (Foto: Juliana O. Silva, fevereiro/2020).

A equipe de saúde realiza "visitas" a cada quatro dias nas aldeias do rio Ituí: saindo e retornando no mesmo dia para a BAPE, onde permanece até a próxima visita. Por um lado, em casos de emergência nas aldeias korubo, esse período entre as visitas é encurtado; por outro, em casos de abastecimento das embarcações, trocas de equipes e transporte de imunobiológicos das cidades de Tabatinga ou Atalaia do Norte (AM) para a BAPE, esse intervalo estende-se. ${ }^{13}$

Nas visitas, a equipe de saúde avalia os Korubo, coleta lâminas de sangue para diagnóstico de malária, realiza pesagens em gestantes e crianças, administra imunizações e medicamentos e, a depender do caso, solicita a "remoção" dos pacientes. Eis o ponto central dessa reflexão. As remoções são saídas dos pacientes korubo da aldeia para "observação" e "tratamento" na BAPE e/ou cidade, sobretudo, Tabatinga, Amazonas.

Os pacientes korubo removidos para a BAPE acomodam-se numa estrutura separada da UBSI, inicialmente planejada para atividades educativas, chamada "Chapéu de Zinco", feita de madeira e zinco. Os sintomas de um paciente "em observação" na BAPE são avaliados pela equipe de saúde e, caso haja um diagnóstico, passa ao "tratamento": ingestão de medicamentos administrados pela equipe. ${ }^{14}$

A logística do atendimento à saúde dos recém-contatados envolve dois fluxos contínuos entre BAPE-aldeia-cidade: o da equipe de saúde e o dos Korubo. Atualmente, após o registro de casos da COVID-19 em Tabatinga e Atalaia do Norte, a circulação dos Korubo para cidade está restrita, porém, o mesmo não ocorre em relação à BAPE.

\footnotetext{
13 Nessas situações, a equipe de saúde desloca-se da BAPE à cidade, pois, na UBSI não há estrutura para conservação de imunobiológicos em temperatura ideal. Os abastecimentos ocorrem a cada 15-20 dias e, a depender da dinâmica de atendimento e do respectivo gasto de combustível, tornam-se mais frequentes.

14 Os conceitos "tratamento" e "observação" são pilares do funcionamento da equipe de saúde, cruciais para compreendermos as dinâmicas aldeia-BAPE-cidade. A passagem ou não entre os estados de observaçãotratamento determina a mobilidade dos pacientes: o retorno para a aldeia, a permanência na BAPE ou a ida para a cidade.
} 
Entre janeiro/2019 e fevereiro/2020, registrei 68 deslocamentos dos Korubo de recente contato, saídas das aldeias à BAPE e/ou cidade, estritamente para atendimento à saúde. ${ }^{15}$ Considerando o período do registro, 14 meses, é como se a cada mês, ao longo de pouco mais de um ano, cinco pacientes saíssem das aldeias para atendimento à saúde. Considere-se ainda que o número $68 \mathrm{diz}$ respeito aos pacientes, independente se permaneceram ou não em tratamento na BAPE. Somam-se aos pacientes seus acompanhantes.

No caso korubo, em média três pessoas acompanham um paciente. Trata-se de remoções familiares: o paciente é acompanhado pelo cônjuge e filhos e, no caso dos mais velhos ou contatados em 2014-15, algum acompanhante korubo que desempenha o papel de tradutor e, em caso de transporte no motor deles, de motorista. Se considerarmos que cada um dos 68 deslocamentos de pacientes incluiu três acompanhantes, seria o equivalente a 204 trânsitos ao longo de 14 meses, ou seja, índice superior ao número da população korubo no rio Ituí. Isso indica os 11 pacientes reincidentes, pessoas que saíram da aldeia mais de uma vez por motivos de saúde no referido período.

Dos 68 deslocamentos, 20,58\% foram remoções de pacientes, solicitadas pela SESAI, para Tabatinga, e 79,41\% foram deslocamentos das aldeias à BAPE, incluindo as solicitações da SESAI e as iniciativas dos Korubo em busca da equipe de saúde. Dos 54 deslocamentos para a BAPE: 24,07\% foram recomendações da SESAI para observaçãotratamento na BAPE e 75,92\% foram iniciativas dos Korubo de irem à BAPE por motivos de saúde. ${ }^{16}$ Em geral, nos 54 deslocamentos para BAPE, os sintomas e diagnósticos em destaque foram gripe/toxoe (50\%), malária $(18,51 \%)$ e diarreia/ piene $(7,4 \%)$.

Embora tratem de um contexto anterior à pandemia da COVID-19 e à contaminação nas aldeias da TI Vale do Javari, esses dados são relevantes para a reflexão, pois a logística de atendimento à saúde dos Korubo de recente contato permanece praticamente inalterada. Neste artigo, não há espaço para descrição ou análise das distintas motivações sanitárias dos deslocamentos dos Korubo, solicitados ou não pela SESAI, ou ainda, dos perfis dos pacientes e das incidências por aldeias. O que os dados revelam e o que me interessa destacar no momento é que, em meio à pandemia da COVID-19 e a necessidade de isolamento como prevenção, há que se considerar os fluxos de saída dos Korubo de recente contato das aldeias à BAPE para atendimento à saúde.

Nesse contexto pandêmico, chama-nos a atenção o fato de uma BAPE, entradasaída de uma terra indígena, ser considerada um espaço estabelecido de saúde de um povo de contato recente. Não é à toa que a BAPE é mencionada no Plano de Contingência,

\footnotetext{
15 Os Korubo também se deslocam até a BAPE por outros motivos: em busca de combustível, na espera de parentes que estão retornando da cidade ou visita a parentes que estão em tratamento, utilização da radiofonia etc.

$16 \mathrm{O}$ registro dos 54 deslocamentos dos Korubo à BAPE exclui os períodos em que estive na cidade (março/junho/outubro/dezembro) e a "ação" odontológica realizada em agosto/2019, quando pacientes das quatro aldeias receberam atendimento na BAPE. Logo, essa amostra pode ser potencializada.
} 
elaborado pelo DSEI Vale do Javari (2020), como uma das "micro-áreas" de atuação. A Portaria Conjunta $\mathrm{n}^{\mathrm{0}}$ 4.094/2018, mencionada no Plano de Contingência, além de reconhecer a "vulnerabilidade social e epidemiológica" dos isolados e recém-contatados, afirma que a SESAI pode sim dispor das instalações físicas da FUNAI para atender os recém-contatados, desde que "sejam adequadas a essa finalidade" (Capítulo V, \$2 ${ }^{\circ}$ ). A pandemia da COVID-19 nos leva a repensar o conceito de "adequado".

Nem a Portaria, nem o Plano que a ela refere-se mencionam a relação entre os recém-contatados e os pontos de entrada em TIs ou, no caso do Plano, a restrição do fluxo dos recém-contatados para esses locais no contexto da pandemia. O médico Douglas Rodrigues, da Escola Paulista de Medicina da Universidade Federal de São Paulo, já alertara para a vigilância em relação à entrada-saída de pessoas nas TIs. ${ }^{17}$ No caso korubo, acrescento, a vigilância acerca dessa relação de proximidade que os recém-contatados têm com uma BAPE: local inerentemente de passagem, de fiscalização e apreensões, onde é possível que haja eventuais quebras de quarentena.

\section{Algumas considerações}

Diante da COVID-19, os Korubo de recente contato são, em geral, uma população de risco: com cerca de quatro idosos e uma quantidade expressiva de crianças, público altamente vulnerável às doenças respiratórias entre os povos indígenas. Considerando a finalidade da Base, proteção etnoambiental, e os deslocamentos envolvidos no atendimento à saúde dos Korubo, até que ponto é possível assegurar uma rotina de prevenção? Levando em conta a logística dos atendimentos de saúde, com idas-vindas da equipe entre BAPE-aldeia-cidade, é possível manter um isolamento comunitário que garanta a seguridade dos recém-contatados diante da pandemia?

Ademais dos deslocamentos logísticos da equipe de saúde entre BAPE-cidade e dos Korubo entre aldeia-BAPE, consideremos algumas previsões do Plano de Contingência elaborado pelo DSEI Vale do Javari para infecção humana pela COVID-19. Menciona-se a necessidade de monitoramento das síndromes, gripal e respiratória aguda grave, com o auxílio de um Agente Indígena de Saúde (AIS). No caso korubo, não há AIS e as visitas da equipe de saúde às aldeias são realizadas a cada quatro dias, como realizar então o monitoramento previsto?

O Plano reforça ainda a necessidade das medidas de quarentena para equipes da FUNAI e SESAI ingressarem na TI. As quarentenas de 14 dias estavam sendo realizadas em acomodações nas cidades com registro de casos da COVID-19, como Atalaia do Norte e Tabatinga, esta última com índice de 73 óbitos por 100 mil habitantes. ${ }^{18}$ Neste caso, a recomendação seria a realização de testes rápidos. Todavia, a SESAI repassou ao DSEI

\footnotetext{
${ }^{17}$ Fonte: https://amazoniareal.com.br/medico-sanitarista-diz-que-doencas-respiratorias-como-coronavirussao-viloes-do-genocidio-indigena/. Acesso: 17/03/20.

18 Fonte: https://g1.globo.com/am/amazonas/noticia/2020/05/05/amazonas-tem-12-cidades-entre-as-20com-maior-incidencias-de-casos-de-covid-19-no-brasil.ghtml. Acesso: 06/05/20.
} 
apenas 360 testes, segundo relatório de 22/05/2020/SESAI - o equivalente a 5,6\% da população da TI Vale do Javari. Após a contaminação das aldeias no médio rio Javari, ocorrida no mês de junho, as quarentenas passaram a ser realizadas em casa construída para essa finalidade no rio Quixito.

Além das quarentenas dos profissionais dessas duas instituições, há ainda outras equipes que circulam na BAPE. Recordemos que entre 2018-19 a BAPE foi alvo de disparos de invasores cerca de oito vezes. ${ }^{19}$ Devido aos ataques, o Ministério da Justiça e Segurança Pública, por intermédio da Portaria nº882/2019, decretou o emprego da Força Nacional de Segurança Pública (FNSP) em apoio à FUNAI. Essa portaria foi atualizada em nº107/2020/MJSP para prorrogar a atuação da FNSP junto à FUNAI.

Se, por um lado, a FNSP garante alguma seguridade física às pessoas na BAPE, por outro lado, representa também o aumento no contingente de pessoas em trânsito no local, pois tratava-se de um revezamento quinzenal de equipes, cerca de seis pessoas indovindo de Tabatinga. Esse fator foi repensado no decorrer da pandemia da COVID-19, resultando na ampliação das escalas da FNSP.

Enquanto as barreiras sanitárias não são instaladas na TI e os Planos de Contingência não adentram em particularidades dos povos indígenas considerados pelo órgão indigenista oficial como de recente contato - os Korubo e os Tyohom-dyapá na TI Vale do Javari -, com medidas a curto, médio e longo prazo, a observância das quarentenas e dos fluxos de pessoas entre aldeia-BAPE é uma das saídas mais palpáveis e imediatas para resguardar a vida dos Korubo de recente contato diante da COVID-19.

\section{Referências Bibliográficas}

AMORIM, Fabrício. (2018). O papel dos povos indígenas isolados na efetivação de seus direitos: apontamentos para o reconhecimento de suas estratégias de vida. Tipiti: Journal of the Society for the Anthropology of Lowland South America: Vol. 16: n.1, pp. 149-157.

ARISI, Bárbara. (2007). Matis e Korubo: contato e indios isolados, relações entre povos no Vale do Javari, Amazônia. Dissertação de Mestrado - Antropologia Social. Florianópolis: UFSC.

CENTRO DE TRABALHO INDIGENISTA/CTI. (2004). A grave situação das hepatites B e D no Vale do Javari. Dossiê.

CENTRO DE TRABALHO INDIGENISTA - CTI. (2010). Informe sobre a Saúde na Terra Indígena Vale do Javari. Dossiê.

CENTRO DE TRABALHO INDIGENISTA - CTI; Instituto Socioambiental - ISA. (2011). Saúde na Terra Indígena Vale do Javari - diagnóstico médico-antropológico: subsídios e recomendações para uma política de assistência.

19 Fonte: https://g1.globo.com/politica/blog/matheus-leitao/post/2019/11/04/principal-BAPE-da-funaipara-protecao-de-indios-isolados-do-pais-sofre-oitavo-ataque-em-12-meses.ghtml. Acesso em 20/11/19. 
CESARINO, Pedro; WELPER, Elena. (2006). "Epidemias produzem o caos social". RICARDO, Carlos Alberto; RICARDO, Fany (Ed.). Povos Indígenas no Brasil-2001/2005. São Paulo: Instituto Socioambiental.

COUTINHO JUNIOR., Walter. (2008). Hepatopatias no vale do Javari: virulento agravo à saúde indígena e afronta aos direitos humanos. Manaus: MPF. Relatório.

COUTINHO JUNIOR., Walter. (2020). O contágio da covid-19 no Vale do Javari: uma situação de emergência em saúde indígena. Relatório Técnico no 112/2020PGR/SPPEA/ANPA. 6a Câmara de Coordenação e Revisão do Ministério Público Federal.

DISTRITO SANITÁRIO ESPECIAL INDÍGENA VALE DO JAVARI. (2020). Plano de contingência do Distrito Sanitário Especial Indígena Vale do Javari para a infecção humana pelo novo coronavírus (COVID-19). Atalaia do Norte (AM): Ministério da Saúde/Secretaria Especial de Saúde Indígena. Disponível em https://drive.google.com/file/d/1TZp9yBx4mDGNo2WuPCKmeFGAxcA1dDvM/vie $\mathrm{w}$

ERIKSON, Philippe. (1996). La griffe des aïeux: marquage du corps et démarquages ethniques chez les Matis d'Amazonie. Paris: Peeters.

FLECK, David. (2013). Panoan Languages and Linguistics. New York: American Museum of Natural History.

SHEPARD JÚNIOR, Glenn. (2020). "Voluntary Isolation in the Age of Coronavirus". Chacruna, 24/03/2020. Disponível em https://chacruna.net/voluntary-isolation-inthe-age-of-coronavirus/. Último acesso em 03/09/2020

MATOS, Beatriz; MARUBO, Jorge. (2006). Colapso no atendimento provoca retorno de epidemias. CEDI: Povos Indígenas no Brasil-2001/2005.

MÉDICO SEM FRONTEIRAS - MSF. (1999). Projeto de Serviços Sanitários Básicos para Populações Indígenas no Vale do Javari, Estado do Amazonas, Brasil. Relatório.

NASCIMENTO, Hilton.; ERIKSON, Philippe. (2006). “Desastre sanitário”. In: RICARDO, Carlos Alberto; RICARDO, Fany (Ed.). Povos Indígenas no Brasil-2001/2005. São Paulo: Instituto Socioambiental.

NASCIMENTO, Hilton.; PAREDES, Deyce. (2006). A grave epidemia de hepatite $B$ e D no Vale do Javari. Relatório/CTI.

OLIVEIRA, Sanderson. (2009). Preliminares sobre a fonética e a fonologia da lingua falada pelo primeiro grupo de índios Korúbo recém-contatados. Dissertação de Mestrado - Linguística. Brasília: UnB.

RICARDO, Fany; GONGORA, Majoí. (Orgs). (2019). Cercos e resistências: povos indígenas isolados na Amazônia brasileira. $1^{\circ}$. ed. - São Paulo: Instituto Socioambiental.

SAMPAIO, Marcelo Reis; TURCOTTE, Sara; MARTINS, V. F. CARDOSO, E. M; BURATTINI, Marcelo Nascimento. (1996). "Malaria in the indian reservation of 'Vale do Javari', Brazil”. In: Revista Instituto de Medicina Tropical. São Paulo: 38(1). 
SELAU, Maria. (1991). Projeto de Prevenção e Combate à Cólera nas Comunidades Indígenas do Rio Javari. Relatório de pesquisa. Brasília: s/ed. (mimeo)

SILVA, Juliana Oliveira; MARQUES, Rafael de Brito (2020). "Emergência sanitária no Vale do Javari e a situação dos povos de recente contato diante da Covid-19". Observatório dos Direitos Humanos dos Povos Indígenas Isolados e de Recente Contato. Disponível em https://povosisolados.com/2020/06/21/emergencia-sanitariano-vale-do-javari-e-a-situacao-dos-povos-de-recente-contato-diante-da-covid-19/. Acesso em 21/06/20.

TORRES, Luis Felipe. (2020). "Estrategias indígenas y políticas públicas durante la pandemia del COVID-19 en la Amazonía peruana: el caso de Madre de Dios”. Salsa Tipiti. Disponível em https://www.salsa-tipiti.org/covid-19/estrategias-indigenas-ypoliticas-publicas-durante-la-pandemia-del-covid-19-en-la-amazonia-peruana-el-casode-madre-de-dios-5-18-20/. Acesso em 18/05/2020.

VARGAS DA SILVA, Bernardo. (2017). Territorialidade Korubo no Vale do Javari. Dissertação de Mestrado - Sociedade e Cultura na Amazônia. Benjamin Constant: UFAM.

\section{sobre a autora}

\author{
Juliana Oliveira Silva \\ É doutoranda e mestra em Antropologia Social pelo \\ Programa de Pós-Graduação em Antropologia Social do \\ Museu Nacional da Universidade Federal do Rio de Janeiro. \\ Também é bacharela em Ciências Sociais pela Universidade \\ Federal do Maranhão.
}

